\title{
Generation, functional annotation and comparative analysis of black spruce (Picea mariana) ESTs: an important conifer genomic resource
}

\author{
Ishminder K Mann ${ }^{1}$, Jill L Wegrzyn ${ }^{3}$ and Om P Rajora ${ }^{1,2^{*}}$
}

\begin{abstract}
Background: EST (expressed sequence tag) sequences and their annotation provide a highly valuable resource for gene discovery, genome sequence annotation, and other genomics studies that can be applied in genetics, breeding and conservation programs for non-model organisms. Conifers are long-lived plants that are ecologically and economically important globally, and have a large genome size. Black spruce (Picea mariana), is a transcontinental species of the North American boreal and temperate forests. However, there are limited transcriptomic and genomic resources for this species. The primary objective of our study was to develop a black spruce transcriptomic resource to facilitate on-going functional genomics projects related to growth and adaptation to climate change.

Results: We conducted bidirectional sequencing of cDNA clones from a standard cDNA library constructed from black spruce needle tissues. We obtained 4,594 high quality (2,455 5' end and 2,139 3' end) sequence reads, with an average read-length of $532 \mathrm{bp}$. Clustering and assembly of ESTs resulted in 2,731 unique sequences, consisting of 2,234 singletons and 497 contigs. Approximately two-thirds (63\%) of unique sequences were functionally annotated. Genes involved in 36 molecular functions and 90 biological processes were discovered, including 24 putative transcription factors and 232 genes involved in photosynthesis. Most abundantly expressed transcripts were associated with photosynthesis, growth factors, stress and disease response, and transcription factors. A total of 216 full-length genes were identified. About 18\% (493) of the transcripts were novel, representing an important addition to the Genbank EST database (dbEST). Fifty-seven di-, tri-, tetra- and penta-nucleotide simple sequence repeats were identified.

Conclusions: We have developed the first high quality EST resource for black spruce and identified 493 novel transcripts, which may be species-specific related to life history and ecological traits. We have also identified full-length genes and microsatellite-containing ESTs. Based on EST sequence similarities, black spruce showed close evolutionary relationships with congeneric Picea glauca and Picea sitchensis compared to other Pinaceae members and angiosperms. The EST sequences reported here provide an important resource for genome annotation, functional and comparative genomics, molecular breeding, conservation and management studies and applications in black spruce and related conifer species.
\end{abstract}

Keywords: Picea mariana, Expressed sequence tag, Gene discovery, Gene expression, Gene ontology, Microsatellites

\footnotetext{
* Correspondence: Om.Rajora@unb.ca

${ }^{2}$ Faculty of Forestry and Environmental Management, University of New

Brunswick, P.O. Box 44000, 28 Dineen Drive, Fredericton, NB E3B 5A3, Canada

Full list of author information is available at the end of the article
} reproduction in any medium, provided the original work is properly cited. The Creative Commons Public Domain Dedication waiver (http://creativecommons.org/publicdomain/zero/1.0/) applies to the data made available in this article, unless otherwise stated. 


\section{Background}

In non-model species with large genome size, EST (expressed sequence tag) sequencing and their annotation can provide the first step towards understanding the transcriptome and expression patterns of specific genes, which can complement the whole genome sequencing, and can assist with genome sequence annotation. Traditionally, EST sequencing was conducted with the Sanger sequencing system [1-5]. More recently, next-generation sequencing (NGS) platforms have been used to generate enormous amounts of genome and transcriptome sequences [6-10]. NGS methods facilitate whole transcriptome sequencing at a fraction of the time and cost previously required for the Sanger method [11,12]. However, commonly used NGS platforms produce shorter reads and/or reduce the quality per base call [13]. The improved length and accuracy of reads obtained from Sanger sequencing can complement NGS workflows. This technology can assist in validating the NGS platform sequences by serving as a reference by which short reads can be aligned and corrected [6]. Therefore, EST sequences derived from the Sanger method are still a valuable resource in the NGS era.

Conifers have a large genome size ( 18-35 Gbp) and are ecologically and economically important, long-lived plants. They form a major part of the northern boreal and temperate forests, which constitute the major biome of the world. The genus Pinus (pine) and Picea (spruce) are two important genera among conifers. Black spruce (Picea mariana (Mill.) B.S.P.) is a widely-distributed transcontinental species of the North American boreal and temperate forests with high ecological and economic importance [14]. Black spruce is one of the most important softwood species for the production of pulp and paper in Canada [15]. It is an early successional species and has a corresponding suite of species-specific life history, growth, eco-physiological and adaptive traits [14]. The estimated haploid genome size of black spruce is about $17.5 \mathrm{Gbp}$, with $1 \mathrm{C}$ contents of $17.4 \mathrm{pg}$ [16].

As of, January $1^{\text {st }}, 2013$ dbEST release (130101), there were approximately 74.19 million ESTs from 2,473 species available in the GenBank at the National Centre for Biotechnology Information (NCBI) [17]. In conifers, the major EST contributing species are loblolly pine - Pinus taeda $(328,662)$, followed by white spruce - Picea glauca $(313,110)$ and Sitka spruce - Picea sitchensis $(186,637)$. Among spruce species, white spruce has the maximum number of ESTs, followed by $P$. sitchensis and P. engelmannii X P. sitchensis. Recently 27,720 unique cDNA clusters (unigene set) have also been reported for $P$. glauca [18]. Also, very recently, draft genomes of Norway spruce (Picea abies) and white spruce have been published $[9,10]$. However, the black spruce transcriptome is not yet fully characterized and only 4 ESTs and $699 \mathrm{cDNA}$ sequences are reported within the
NCBI's dbEST (excluding ESTs reported from the current study). Due to a number of life history, morphological, adaptive, eco-physiological, and insect resistance traits and phylogenetic differences of black spruce from white spruce and Sitka spruce $[14,19-21]$, we expect some unique genes in the black spruce transcriptome. Black spruce is an early successional shade-intolerant species whereas white spruce and Sitka spruce are late successional shade-tolerant species. Black spruce can grow in poor conditions, such as bogs, whereas white spruce grows on well-drained soils. These species-specific traits affirm a need to sequence and characterize the black spruce transcriptome.

Much of the EST sequencing in conifers has been performed using wood forming tissues and secondary xylem due to the economic importance of wood $[1,2,4,22-25]$. There are a number of studies that have sequenced transcripts from needle tissues, including: lodgepole pine (Pinus contorta) [6], sugar pine (Pinus lambertiana) [24], loblolly pine [24], maritime pine (Pinus pinaster) [23] and Norway spruce [26]. These studies have provided some basis for the genes expressed in needle tissue; however, more comparative work is needed to understand their role in important metabolic pathways, such as photosynthesis.

The objective of our study was to develop a black spruce transcript resource, and thus, facilitate structural and functional spruce genomics projects related to growth and adaptation. Here, we report the results of the first EST sequencing project from black spruce in which cDNA clones were isolated and sequenced from a standard cDNA library constructed from needle tissues in 2002. We conducted bidirectional Sanger sequencing of ESTs to produce high quality, long reads to assist with the identification of fulllength genes. We assembled ESTs into contigs and singletons, and subsequently performed comparative protein annotations with the non-redundant (NR) protein database and UniGene clusters available at NCBI for model plant species. We further conducted nucleotide similarity analysis with EST sequences available from all major plant species (dbEST), as well as species-specific sequences from various gymnosperms and angiosperms. Gene Ontology terms were assigned and the ESTs were manually evaluated for specific categories, including transcription factors and photosynthetic genes. Finally we used black spruce EST data for the detection of simple sequence repeats (SSRs).

\section{Methods}

Plant material and cDNA library construction

Total RNA was extracted from $2 \mathrm{~g}$ of freshly growing needles of three different black spruce seedlings established in the greenhouse at Dalhousie University, following the protocol described in [27]. Quality and quantity of the isolated RNA were determined using a spectrophotometer (SPECTRAmax PLUS, Molecular 
Devices Corporation, Sunnyvale, CA, USA) and extracted RNA was found to be of high quality $\left(\mathrm{OD}_{260} /\right.$ $\mathrm{OD}_{280}=1.82$ ). The quantity of isolated RNA was approximately $120 \mu \mathrm{g}$ per $\mathrm{g}$ of the needle tissue used. The polyA RNA was purified using RNeasy Mini Kit (Qiagen Inc., Mississauga, ON, Canada) following the manufacturer's instructions. The cDNA library was constructed using Creator smart cDNA library construction kit (Clontech Laboratories Inc. CA, USA). The oligo dT primed cDNA inserts were directionally cloned in pDNRLIB vector and transformed using XL-10 gold ultracompetent cells of Escherichia coli. Plasmid DNA was isolated from the transformed white colonies selected from the overnight grown cells on Luria Broth agar plates containing chloramphenicol (30 $\mu \mathrm{g} / \mathrm{ml})$ using QIAprep Spin Miniprep kit (Qiagen Inc. Mississauga, ON, Canada). The quality and quantity of the isolated plasmid DNA was confirmed on $0.8 \%$ agarose gels with known amount of lambda DNA before sequencing.

\section{cDNA sequencing}

Sequencing reactions were performed in a PTC-200 thermal cycler (MJ Research, Reno, NV, USA) using the Thermosequenase fluorescent labeling primer cycle sequencing kit with 7-deaza dGTP (Amersham Pharmacia Biotech, Freiburg, Germany) according to the manufacturer's instructions. The sequencing products were resolved on a LI-COR $4200 \mathrm{~L}$ sequencing system (LI-COR Biosciences, Lincoln, NE, USA). A total of 2,486 cDNA clones were sequenced in both directions using IRD labeled M13F (5' -AAA CAG CTA TGA CCA TGT TCA-3') and M13R (5'-GTA AAA CGA CGG CCA GT-3') primers.

\section{Preliminary sequence processing}

Processing of raw trace files was performed through the customized TreeGenes EST pipeline [28]. Base-calling and quality-assignment of the sequences were conducted with Phred (versions 0.000925.c and 0.020425.c) [29,30]. Low quality bases below Phred20 were masked and vector sequences were trimmed from the ends. The cross_match program was used for this purpose with minmatch 12 and minscore 20 [31]. Sequences with less than 100 highquality bases (Phred20 or better) after trimming and sequences with polyA tails of $\geq 100$ bases were removed from the analysis. The resulting sequence set was compared against the non-redundant (NR) protein database [32] and top ranked BLAST matches to species other than plants with score values $>70$ were flagged as contaminants; no such sequences were found in our sequence dataset. The processed sequences were assembled into contigs and singletons using USEARCH v6.0 [33] with 95\% identity. EST and contig redundancy was calculated as described in Kirst et al. [2]. Simple sequence repeats (SSRs) present in the EST sequences were identified and analyzed using the simple sequence repeat identification Tool (SSRIT) [34]. The parameters were set for detection of perfect di-, tri-, tetra-, and pentanucleotide motifs with a minimum of $10,7,5$, and 4 repeats, respectively.

\section{Comparative sequence analysis}

The following databases were used to perform BLASTX [32] and BLASTN [32] analyses for annotation of the EST singletons and contigs: 1) Arabidopsis thaliana, UniGene Build \#74, 30,633 clusters; 2) Populus UniGene Build\#11, 15,056 clusters; 3) Oryza sativa, UniGene Build \#86, 44,118 clusters; 4) Vitis vinifera, UniGene Build \#13, 22,101 clusters; 5) Physcomitrella patens, UniGene Build \#4, 17,573 clusters; 6) Pinus and Picea, UniGene Build \#13, 61,706 clusters; 7) NR database of GenBank, NCBI release 192, release date October 15, 2012; 8) EST_OTHERS in NCBI download date October 21, 2012; 9) UniProt Plant Protein databank in NCBI download date October 9, 2012. All BLAST searches were subject to an e-value cut-off of $1 \mathrm{e}-05$. In reporting BLAST results, the BLAST score was used which incorporates both the similarity metric and the e-value to provide a representation of the hit's uniqueness and overall similarity to the query sequence. BLASTX searches were targeted against model species while BLASTN searches focused on comparisons against conifer species with public sequence resources. In addition to BLAST annotations, the pipeline-directed Gene Ontology (GO) assignments were conducted from applicable results in the categories of Molecular Function and Biological Process. The hierarchical GO structure was stored locally to resolve consistent levels of annotation. In order to classify sequences into comparable categories, InterPro scan wrappers were applied to generate BRENDA enzyme, SignalP, TMHMM, and PFAM protein domain results. Full-length unique ESTs were identified from BLASTX sequence similarity searches. To be considered full-length, sequence were required to have greater than $80 \%$ identity and include the start codon for the translated protein.

\section{Results and discussion}

\section{EST sequence quality, contigs and unique sequences}

A sequence read length of $>100 \mathrm{bp}$ from either one or both directions was obtained for 2,486 cDNA clones. After sequence processing and removing vector and low quality sequences, a total of 4,594 high quality reads $\left(2,4555^{\prime}\right.$ end and 2,139 $3^{\prime}$ end) were obtained (Table 1$)$. The average read-length of ESTs used for sequence analysis was $532 \mathrm{bp}$. The EST length was distributed from 100 to $500 \mathrm{bp}$ (45\%), 501 to $800 \mathrm{bp} \mathrm{(43 \% )} \mathrm{and} 801$ to 1242 bp (12\%). Sequence length of greater than 800 bp was obtained for one-eighth of our ESTs.

We identified a total of 2,731 unique sequences, consisting of 2,234 singletons and 497 contigs from the assembly of 4,594 overlapping and contiguous quality 
Table 1 Summary of EST sequencing and assembly results

\begin{tabular}{|c|c|}
\hline EST sequences and contigs & Number \\
\hline Total EST sequences & 4,594 \\
\hline Number of $5^{\prime}$ sequences & 2,455 \\
\hline Number of $3^{\prime}$ sequences & 2,139 \\
\hline Number of contigs & 497 \\
\hline Number of singletons & 2,234 \\
\hline Average assembled EST length & 532.5 \\
\hline Number of full-length cDNA sequences & 216 \\
\hline \multicolumn{2}{|l|}{ Number of assembled ESTs with: } \\
\hline Significant BLASTX annotations & 1,717 \\
\hline Significant BLASTX annotations with known function & 1,478 \\
\hline No BLASTX annotation information & 1,014 \\
\hline Average number of sequences per contig & 4.75 \\
\hline \multicolumn{2}{|l|}{ Number of contigs containing: } \\
\hline 2 ESTs & 237 \\
\hline 3 ESTs & 91 \\
\hline 4 ESTs & 51 \\
\hline 5 ESTs & 28 \\
\hline 6 ESTs & 17 \\
\hline 7 ESTs & 20 \\
\hline 8 ESTs & 7 \\
\hline 9-11 ESTs & 19 \\
\hline 12-14 ESTs & 9 \\
\hline 15-17 ESTs & 6 \\
\hline 18-20 ESTs & 5 \\
\hline 22-25 ESTs & 3 \\
\hline$>25$ ESTs & 4 \\
\hline
\end{tabular}

reads (Table 1 ). The average length of singletons, and contigs, was $526 \mathrm{bp}$, and $560 \mathrm{bp}$, respectively. The average and maximum number of ESTs in a contig was 4.75, and 208, respectively (Table 1; Figure 1). The average GC content of the unique sequences set is $46.3 \%$. All of the 4,594 high quality EST sequences have been deposited into GenBank under the accession numbers dbEST JZ079173 - JZ083766. They have also been submitted to the TreeGenes database [35].

EST redundancy in the present study was $51 \%$, which is lower than estimates of 59 to $85 \%$ reported in other representative conifer studies (Table 2), even though our ESTs were sequenced from a standard non-normalized cDNA library versus normalized cDNA libraries used in most of the other studies. The lower EST redundancy could be due to the fact that relatively small number of sequences from the cDNA library in this study. As the number of ESTs sequenced from a single cDNA library increases, the percent EST redundancy also increases. Inevitable causes of redundancy in cDNA libraries are non-uniform abundance of mRNAs from different genes [36], presence of paralogous genes, and members of multigene families [37]. On the other hand, the redundancy inherent in standard cDNA libraries improves the assemblies as overlapping ESTs from a single gene can be aligned to generate a single contig $[36,38,39]$. The contig redundancy of $4.7 \%$ in our study was similar to that observed in other representative conifer tree species (Table 2). Thus, the quality of our EST sequences appears to be quite high. It should be noted that it is difficult to make comparisons between numbers of transcripts among different projects and genera as they are influenced by the genome and/or transcriptome size of the study species. In addition, these comparisons are influenced by the assembly method [24] and the number of input reads.

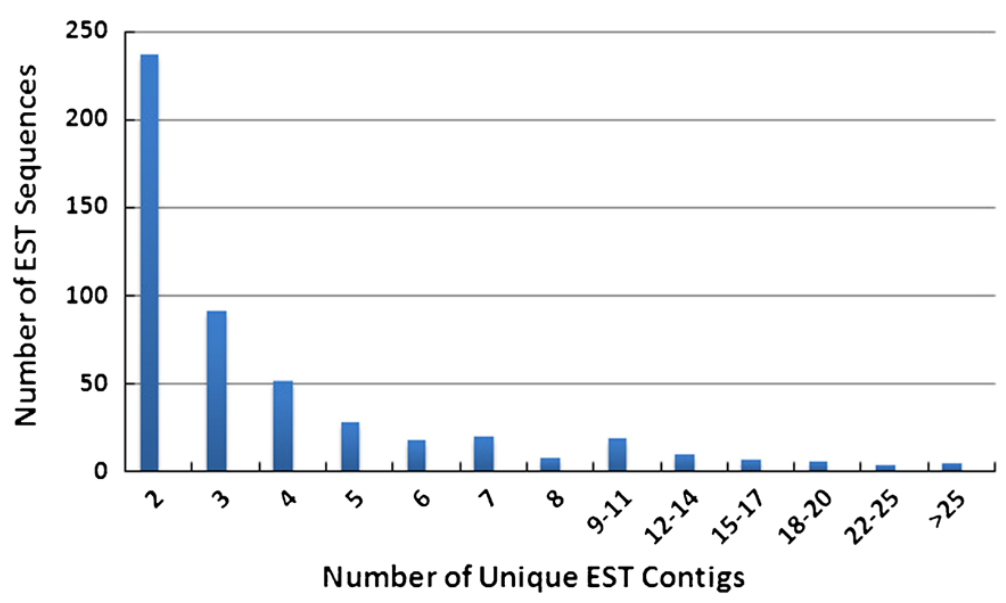

Figure 1 Distribution of individual 5' and 3' EST sequences among the clustered contigs. 
Table 2 Comparison of EST sequencing statistics with representative Picea and Pinus studies

\begin{tabular}{|c|c|c|c|c|c|c|c|c|c|}
\hline Species & $\begin{array}{l}\text { Sequencing } \\
\text { method }\end{array}$ & $\begin{array}{l}\text { Average } \\
\text { length, bp }\end{array}$ & $\begin{array}{l}\text { Number of } \\
\text { ESTs (a) }\end{array}$ & $\begin{array}{l}\text { Singletons } \\
\text { (b) }\end{array}$ & $\begin{array}{l}\text { Contigs } \\
\text { (c) }\end{array}$ & $\begin{array}{l}\text { No of unigenes } \\
\qquad(b+c)\end{array}$ & $\begin{array}{c}\text { EST } \\
\text { redundancy,\% } \\
{[(a-b) / a]}\end{array}$ & $\begin{array}{c}\text { Contig redundancy } \\
{[(a-b) / c]}\end{array}$ & Reference \\
\hline $\begin{array}{l}\text { Picea } \\
\text { mariana }\end{array}$ & Sanger & 532 & 4,594 & 2,234 & 497 & 2,731 & $51 \%$ & 4.7 & $\begin{array}{l}\text { Current } \\
\text { study }\end{array}$ \\
\hline $\begin{array}{l}\text { Picea } \\
\text { glauca }\end{array}$ & Sanger & 615 & 49,101 & 7,224 & 9,354 & 16,578 & $85 \%$ & 4.5 & [25] \\
\hline $\begin{array}{l}\text { Picea } \\
\text { sitchensis }\end{array}$ & Sanger & - & 147,146 & 26,804 & 19,941 & 46,745 & $82 \%$ & 6.0 & [4] \\
\hline $\begin{array}{l}\text { Pinus } \\
\text { taeda }\end{array}$ & Sanger & 364 & 59,797 & 12,307 & 8,070 & 20,377 & $79 \%$ & 5.9 & [2] \\
\hline $\begin{array}{l}\text { Pinus } \\
\text { contorta }\end{array}$ & 454 & 306 & 586,732 & 239,793 & 63,657 & 303,450 & $59 \%$ & 5.5 & {$[6]$} \\
\hline
\end{tabular}

Functional gene annotations for unique transcript sequences and gene discovery

Translated nucleotide to protein comparisons were made for the 2,731 P. mariana unique sequences (2,234 singletons and 497 contigs) against the non-redundant (NR) protein database. 1,319 (59\%) of 2,234 singletons and 398 (80.1\%) of 497 contigs, had significant BLASTX hits to known proteins, yielding annotations for 1,717 (62.8\%) black spruce unique sequences (Table 1; Additional file 1: Table S1). As expected, the percentage of contigs (80.1\%) showing significant similarity with the NR database was higher than singletons (59\%). This may be due to greater sequence lengths of the contigs in comparison to shorter singletons. Of the 1,717 annotated unique sequences, 1,478 (54\%) represented sequences with known gene functions. In all cases, the most significant, informative annotation was selected. The remaining 239 annotated sequences had annotations that were predicted, hypothetical, or unknown (Additional file 1: Table S1). No contaminants were found after analysis of BLASTX results as the cDNA library was developed from fresh needles of greenhouse grown seedlings.

A total of 1,014 (37.1\%) sequences had no significant BLASTX hits with the NR protein database. The sequence divergence among gymnosperms and angiosperms is a limiting factor for gene annotation in conifers. Similar statistics were obtained for BLASTX similarity analysis of ESTs against publically available databases for white spruce [25] Sitka spruce [4], and Norway spruce [26], which reported no annotations for $15-30 \%$ of the transcripts. These results demonstrate that available datasets are not sufficient for annotation of conifer transcripts. In theory, these un-annotated sequences $(1,014)$ could be $P$. mariana specific transcripts or short segments of genes that would be recognized as homologs if more substantial sequences sets were available. Perhaps, these sequences represent regions of proteins that have diverged too much and escaped our similarity search criteria. Finally, these un-annotated sequences could represent partial transcripts with mostly UTRs which, in general, show lower degree of conservation among species. Following the initial analysis of ESTs with the NR database, sequences were annotated against the highly curated plant protein UniProt databank and produced a total of 1,478 significant annotations with known functions (Table 1 and Additional file 1: Table S1). The gene annotations from ESTs in this study represent only a portion of gene repertoire in $P$. mariana, more transcriptome sequencing is needed to identify the needle tissue transcriptome.

Predicted proteins from the first whole genome sequence of Norway spruce have become available [9]. However, the Norway spruce genome assembly and protein predictions are at the very first stage, whereas we have used highly curated and reliable plant protein and NR protein databases for annotation of our black spruce unique contigs and singletons. Thus, the functional annotations reported here, although conservative, should be quite reliable. Also, the first draft genome of white spruce is published [10] but there is no information available on its predicted proteins. In future, with the availability of advance generations of Norway spruce genome assembly and identification of functional proteins, the black spruce unique transcriptome sequences should be analyzed against the Norway spruce and other conifers (if available) functionally analyzed and predicted proteins. This may provide information if an EST is a member of a longer protein that is actually or predictably expressed.

The BLASTX comparisons of $P$. mariana 3 ' singletons, $5^{\prime}$ singletons, and contigs were also conducted against the protein sequences of five sequenced plant genomes (Arabidopsis, Populus, Oryza sativa, and Vitis vinifera) and moss (Physcomitrella patens) (Figure 2; Additional file 2: Table S2). In all species, contigs and 5' singletons showed higher similarity (0-45\%) with the species-specific peptides than 3 ' singletons (0.2-23\%) (Figure 2A). The 3 ' singletons obtained the most annotations with a BLAST score range from 50-99. Between 

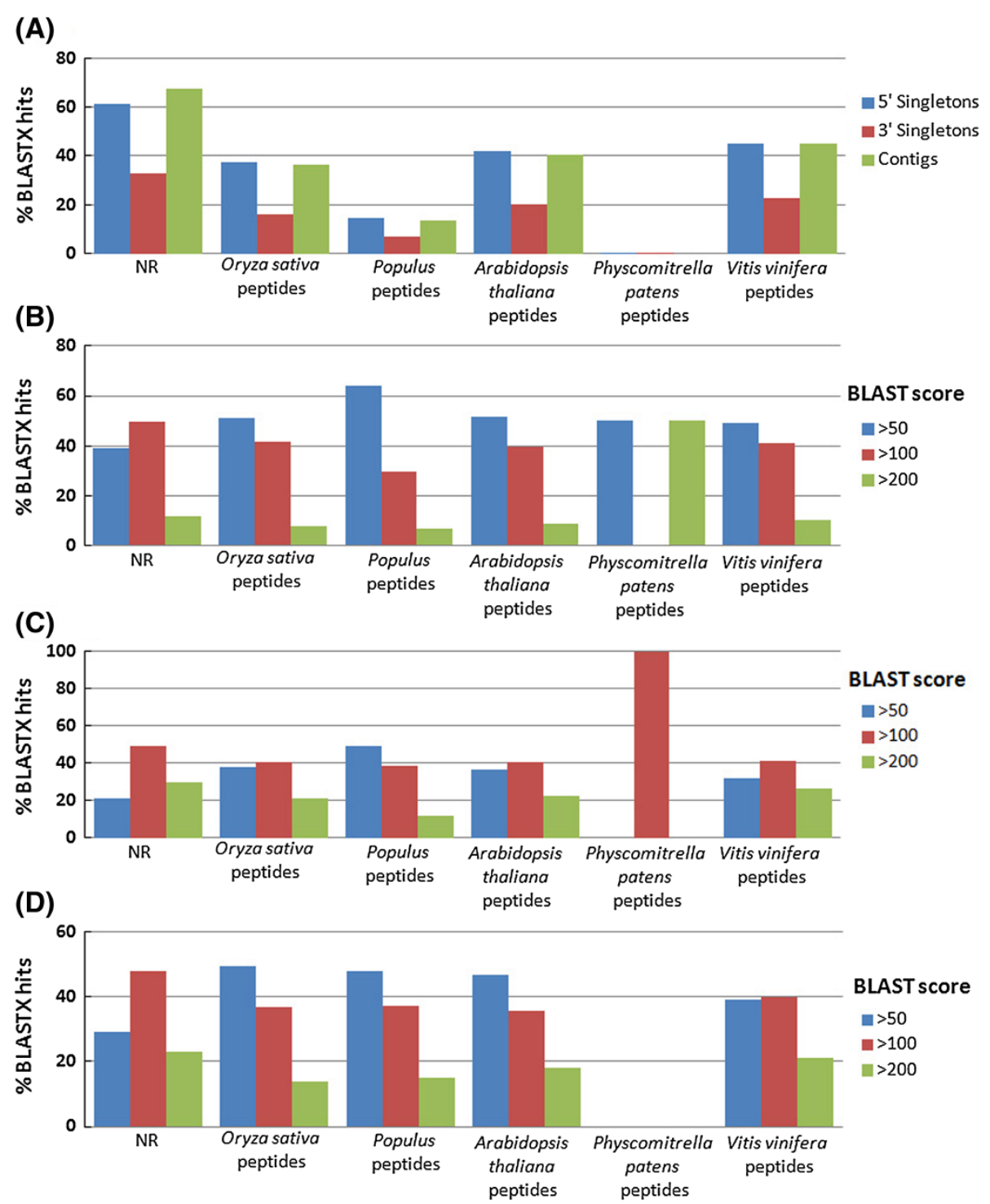

Figure 2 Conservation between Picea mariana unique sequences and peptides from five model plant species and non-redundant protein database: BLASTX searches were performed against: Arabidopsis thaliana, Populus, Vitis vinifera, Oryza sativa, and

Physcomitrella patens. (A) Percentage of Picea mariana unique sequences showing similarity with peptides from six databases (>50 score). Contigs showed the highest number of hits to all five model plant species databases followed by $5^{\prime}$ singletons and then $3^{\prime}$ singletons. (B-D). $3^{\prime}$ singletons, 5' singletons and contigs were analyzed separately using low (score > 50), medium (score > 100) and high (score > 200) BLAST stringency thresholds. (B) The 3' EST singletons had a much greater number of annotations with the model databases in the $>50$ score category ranging from $49 \%$ to $64 \%$. (C) The 5' EST singletons had the greatest number of hits with scores $>100$. (D) The EST contigs had the largest number of high scoring hits (> 50) with representation across most of the five model plant species databases.

$49 \%$ and $64 \%$ of the 3 ' singletons contained an annotation with Arabidopsis, Populus, Oryza sativa, Vitis vinifera, and Physcomitrella patens at score range of 50-99 (Figure 2B). However, 5' singletons had a larger percentage of BLAST hits with a score range of 100-199 (Figure 2C). Contigs and $5^{\prime}$ singletons, had the best alignments with scores $>200$ in all model plant species queried (Figure 2C,D). The greatest number of black spruce contig annotations, with a score range of 50-99 ( 50\%), were obtained from the comparisons with the Populus and Oryza sativa proteins. A previous study involving $5^{\prime}$ singletons, 3 ' singletons, and contigs for white spruce and Sitka spruce, showed a higher percentage of BLASTX similarity with the same angiosperm species as in our study [4]. The percentage of white spruce and Sitka spruce $5^{\prime}$ singletons (74-82\%) showing BLASTX similarity was higher than 3 ' singletons (60-68\%) [4]. In contrast, only $49.7 \%$ of loblolly pine ESTs showed significant BLASTX hits with Arabidopsis peptides [2]. Based on the functional gene annotation analysis, 
$P$. mariana transcripts showed higher annotation rates with angiosperms peptides used in the present study than with moss peptides. It may be due to the fact that conifers are phylogenetically closer to angiosperms than to mosses [40]. Black spruce transcripts are expected to show the highest annotations with highly curated spruce and pine peptide database when it becomes publicly available.
Gene ontology classification, full-length genes, and gene families

Gene Ontology (GO) results were assigned to describe the functional distribution within the EST unique sequences derived from P. mariana needle tissue (Figures 3A and B; Additional file 1: Table S1). A total of 533 unique sequences were associated with at least one molecular function term and 572 sequences were associated with at least

\section{(A) Molecular function}

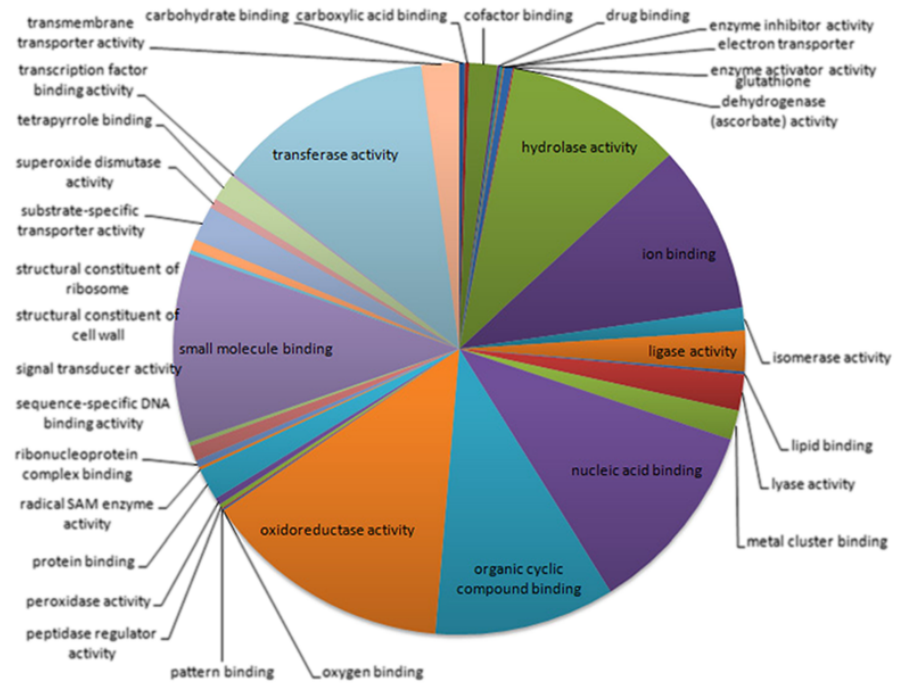

\section{(B) Biological process}

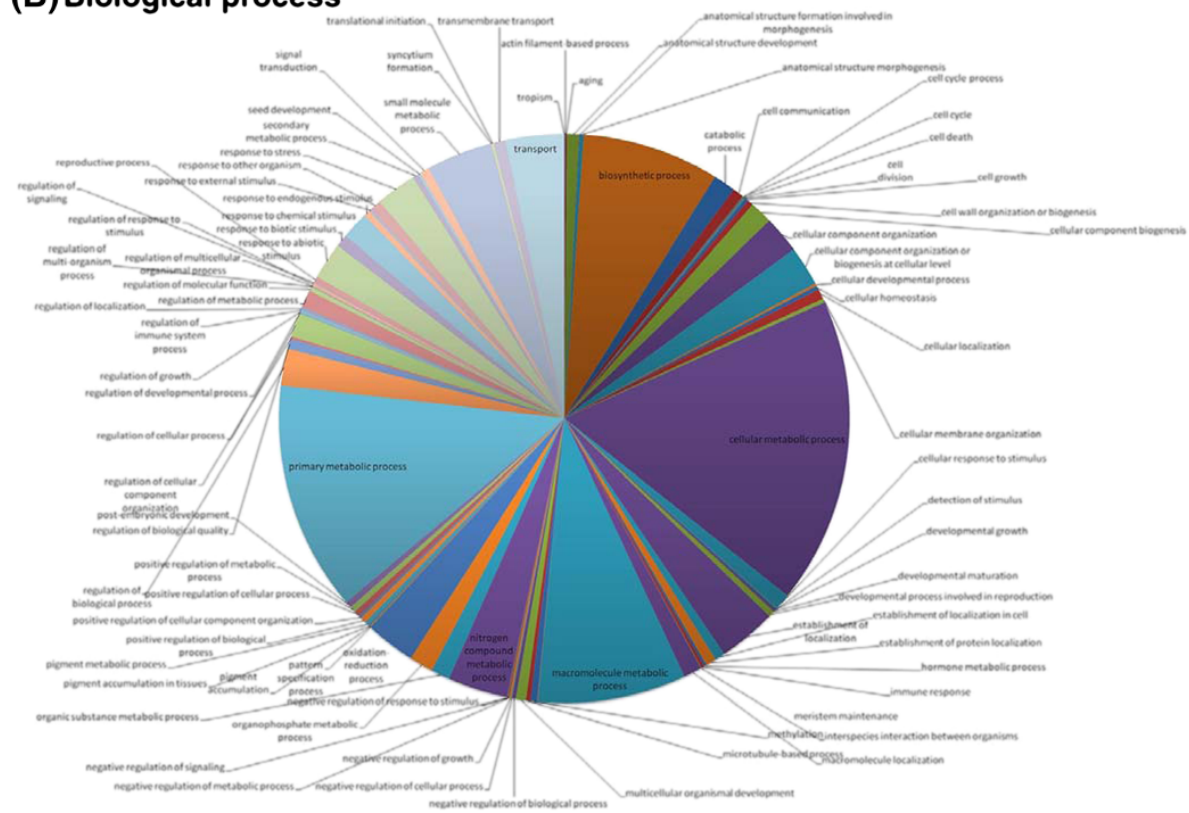

Figure 3 Gene ontology classification of Picea mariana unique sequences: BLASTX at an e-value cut-off of $1 \mathrm{e}-05$ were performed against UniProt's plant protein databank. This was used in conjunction with InterProScan to identify domains linked to GO terms. Terms were standardized to hierarchy level 4 and 5 in order to compare the results across the annotations. (A) A total of 533 unique sequences were associated with at least one molecular function term. (B) A total of 572 unique sequences were associated with at least one biological process term. 
one biological process term (Figures 3A and B; Additional file 1: Table S1). Molecular function assignment revealed that oxidoreductase activity, transferase activity, ion binding and nucleic acid/nucleotide binding accounted for the largest portion of the $P$. mariana unique genes identified ( $47 \%$ combined). Among the ion binding proteins, the majority were small metal ion binding proteins such as metallotheonins, zinc and calcium binding proteins. These genes are involved in stress response [41] and protect cells from toxic metal and assist in metal transport $[42,43]$. Metallothioneins are able to sequester excess amounts of metal ions, and participate in homeostasis and antioxidant functions [44]. Various nucleic acid binding proteins were also targeted with high frequency as they are important components of transcriptional machinery of cells [45]. Previous study involving Quercus spp. contigs also reported nucleotide binding as abundant GO term in terms of molecular function [13]. Other significant categories included hydrolase activity, small molecule binding and organic cyclic compound binding ( $10 \%$ each) (Figure 3A). It is worth noting that although the EST number in our study is relatively small, genes involved in 36 molecular functions could be identified.
Biological process describes the major biochemical pathways that the sequences may be involved in (a much higher resolution than molecular function). The primary categories in our study include cellular metabolic process (17\%), primary metabolic process $(13 \%)$, macromolecule metabolic process $(8 \%)$, and biosynthetic process $(8 \%)$ (Figure 3B). The results from the functional distribution highlight that transcripts from diverse categories are represented in $P$. mariana unique sequences. The molecular functions and biological processes assigned for the black spruce unique contigs and singletons are consistent with the metabolic pathways active during vigorously-growing black spruce seedlings in the greenhouse conditions from which samples for RNA preparation were collected. The molecular function and biological process Gene Ontology terms are also consistent with the similar results reported in other studies that used needles for EST or transcriptome sequencing $[6,23,24,26]$.

A combination of BLAST annotations, GO terms, and supplemental InterProScan data was used to generate lists of gene families of interest. Two of the groups highlighted here include transcription factors (Table 3 ) and genes involved in the photosynthetic pathway

Table 3 EST singletons and contigs annotated as putative transcription factors

\begin{tabular}{|c|c|c|}
\hline EST contig/singlet & Annotation sequence identifier & Annotation description \\
\hline estPama_needle_Contig7 & gi|356520192|ref|XP_003528748.1| & Transcription factor 25 -like \\
\hline estPama_needle_Contig151 & gi|225438387|ref|XP_002275126.1| & RNA polymerase II transcriptional coactivator KIWI \\
\hline estPama_needle_2137-700_5 & gi|297794475|ref|XP_002865122.1| & Myb family transcription factor \\
\hline estPama_needle_2089-700_5 & gi|357125278|ref|XP_003564322.1| & Transcription elongation factor 1 homolog isoform \\
\hline estPama_needle_BSc1-839-700_5 & gi|356500773|ref|XP_003519205.1| & Transcription initiation factor IIA subunit 2-like \\
\hline estPama_needle_Contig232 & gi|357144617|ref|XP_003573355.1| & Transcription factor ILR3-like \\
\hline estPama_needle_Contig326 & gi|255547594|ref|XP_002514854.1| & Transcription factor, putative \\
\hline estPama_needle_Contig314 & gi|358346858|ref|XP_003637481.1| & Transcription factor \\
\hline estPama_needle_Contig320 & gi|115470937|ref|NP_001059067.1| & Similar to C-Myc binding protein \\
\hline estPama_needle_BSC1-987-800_3 & gi|225461347|ref|XP_002281902.1| & PAP-specific phosphatase HAL2-like \\
\hline estPama_needle_1584-700_5 & gi|115470937|ref|NP_001059067.1| & Similar to C-Myc binding protein \\
\hline estPama_needle_1817-700_5 & gi|225437251|ref|XP_002282315.1| & Thylene-responsive transcription factor 7-like \\
\hline estPama_needle_2311-700_5 & gi|302840754|ref|XP_002951923.1| & Transcription factor jumonji domain-containing protein \\
\hline estPama_needle_1788-700_5 & gi|15233968|ref|NP_195574.1| & Transcription repressor MYB4 \\
\hline estPama_needle_Contig490 & gi|255547594|ref|XP_002514854.1| & Transcription factor, putative \\
\hline estPama_needle_BSc1-785-700_5 & gi|255585312|ref|XP_002533354.1| & WRKY transcription factor, putative \\
\hline estPama_needle_BSC1-935-800_3 & gi|225438387|ref|XP_002275126.1| & RNA polymerase II transcriptional coactivator KIWI \\
\hline estPama_needle_1371-700_5 & gi|255561893|ref|XP_002521955.1| & Associate of C-myc, putative \\
\hline estPama_needle_2143-800_3 & gi|357494843|ref|XP_003617710.1| & mTERF domain-containing protein \\
\hline estPama_needle_2512-700_5 & gi|359494595|ref|XP_002262881.2| & Nuclear transcription factor $Y$ subunit C-9 \\
\hline estPama_needle_1540-700_5 & gi|334183649|ref|NP_001185317.1| & Transcription elongation factor SPT6 \\
\hline estPama_needle_2467-700_5 & gi|302840754|ref|XP_002951923.1| & Transcription factor jumonji domain-containing protein \\
\hline estPama_needle_BSc1-839-800_3 & gi|255572854|ref|XP_002527359.1| & Transcription initiation factor iia (tfiia), gamma chain, putative \\
\hline estPama_needle_BSc1-781-700_5 & gi|356547095|ref|XP_003541953.1| & WRKY transcription factor 6 \\
\hline
\end{tabular}


(Additional file 3: Table S3). Transcription factors are DNA-binding sequence-specific proteins that interact with the promoter sequences of target genes and modulate the gene expression [46]. A total of 24 putative transcription factor sequences were identified based on the GO term assignment of $P$. mariana unique sequences. Majority of the transcription factors were represented by myc, myb, and WRKY domains. These transcription factors families have also been reported in the white spruce EST collection $[18,25]$. They are key regulators of various biological processes involved in growth and development $[47,48]$. Also, they are expressed in response to various biotic and environmental stresses encountered by needles during their life cycle $[48,49]$. Some WRKY proteins have been found to be involved in the signal transduction pathway [49].

Since the cDNA library was constructed from needle tissues, genes related to photosynthesis were expected to be abundantly expressed. A total of 232 P. mariana unique transcripts related to photosynthetic pathway were identified (Additional file 3: Table S3). This group included chlorophyll a/b binding protein, light-harvesting complex proteins, photosystem I and II reaction center proteins, ribulose bisphosphate carboxylase (RuBisCo), oxygenevolving enhancer protein, granule-bound starch synthase and nucleoside diphosphate. In plants, RuBisCo is more abundant during the day when it is transcriptionally regulated by the light receptor phytochrome, thus fixing carbon dioxide in photosynthesis [50]. We collected needle samples for RNA extraction during daytime.

BLAST results against individual species as well as the NR repository provided details on the 216 full-length ESTs identified (Additional file 4: Table S4). Of these, $32 \%$ had annotations in three of the five model plant

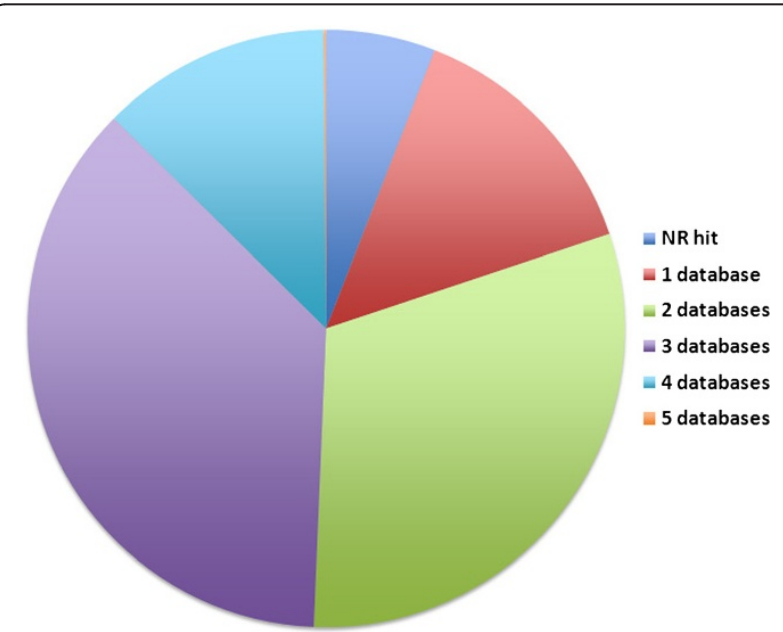

Figure 4 Distribution of full-length cDNAs according to BLASTX hits in the number of species-specific repositories: Of the $\mathbf{2 1 6}$ full-length genes identified, the majority $(90 \%)$ had significant annotations in all five datasets at an e value (expected value) cut-off of $1 e-05$. species (Figure 4). The 216 full-length gene sequences were represented by 67 contigs, $1315^{\prime}$ singletons, and 18 3' singletons. The full-length cDNA sequences are an important resource for characterization of individual genes and members of multigene families, as well as for functional and comparative genomics. Additionally, they

Table 4 Estimation of gene expression: unique EST sequences with $>10$ ESTs

\begin{tabular}{|c|c|c|}
\hline Putative protein identification & $\begin{array}{l}\text { Number of unique } \\
\text { EST sequences }\end{array}$ & $\begin{array}{l}\text { Number } \\
\text { of ESTs }\end{array}$ \\
\hline Non-specific lipid-transfer protein & 10 & 77 \\
\hline $\begin{array}{l}\text { Bet } \vee \text { I allergen family protein. } \\
\text { (Os04t0465600-01) }\end{array}$ & 2 & 40 \\
\hline $\begin{array}{l}\text { Ribulose bisphosphate carboxylase } \\
\text { small chain } 1 \mathrm{~A}\end{array}$ & 4 & 35 \\
\hline Antimicrobial peptide 1 & 2 & 30 \\
\hline $\begin{array}{l}\text { Non-protein coding transcript. } \\
\text { (Os07t0139600-01), partial }\end{array}$ & 9 & 28 \\
\hline Histone $\mathrm{H} 3$ & 4 & 24 \\
\hline Light-harvesting complex & 4 & 24 \\
\hline Germin-like protein 8-14-like & 2 & 21 \\
\hline Metallothionein-like protein 3B-like & 6 & 21 \\
\hline $\begin{array}{l}\text { Photosystem I reaction center subunit } \\
V\end{array}$ & 2 & 21 \\
\hline Photosystem II subunit X & 3 & 21 \\
\hline Cell wall-associated hydrolase, partial & 8 & 20 \\
\hline $\begin{array}{l}\text { LOW QUALITY PROTEIN: photosystem II } \\
10 \text { kDa Polypeptide, chloroplastic-like }\end{array}$ & 1 & 18 \\
\hline $\begin{array}{l}\text { Translation machinery associated } \\
\text { protein TMA7 }\end{array}$ & 2 & 17 \\
\hline $\begin{array}{l}\text { Photosystem I reaction center subunit } \\
\mathrm{N} \text {, chloroplast precursor, putative }\end{array}$ & 2 & 15 \\
\hline Protein ralf-like 34 & 3 & 15 \\
\hline $\begin{array}{l}\text { Transmembrane protein TPARL, } \\
\text { putative }\end{array}$ & 1 & 13 \\
\hline $\begin{array}{l}\text { Hypothetical protein BrnapMp036 } \\
\text { (mitochondrion) }\end{array}$ & 3 & 13 \\
\hline Hypothetical protein EAAG1_11607 & 1 & 13 \\
\hline ATP synthase subunit beta & 3 & 11 \\
\hline $\begin{array}{l}\text { Metallothionein-like protein 2-like } \\
\text { isoform } 2\end{array}$ & 1 & 11 \\
\hline Ribosomal protein S14 (chloroplast) & 3 & 11 \\
\hline $\begin{array}{l}\text { Auxin-binding protein ABP19a } \\
\text { precursor, putative }\end{array}$ & 1 & 10 \\
\hline $\begin{array}{l}\text { Photosystem II } 5 \text { kDa protein, } \\
\text { chloroplastic-like }\end{array}$ & 1 & 10 \\
\hline $\begin{array}{l}\text { Similar to Anth (Pollen-specific } \\
\text { desiccation-associated LLA23 protein). } \\
\text { (Os11t0167800-01) }\end{array}$ & 2 & 10 \\
\hline $\begin{array}{l}\text { Chlorophyll a-b binding protein M9, } \\
\text { chloroplastic precursor }\end{array}$ & 1 & 10 \\
\hline Photosystem I subunit $O$ & 2 & 10 \\
\hline
\end{tabular}


are essential resources for downstream annotation of related conifer genomic sequences.

\section{Gene expression and highly abundant transcripts}

A preliminary estimation of gene expression can be given by the frequency distribution of the ESTs representing a gene in the library. Among the annotated sequences, 30 contained at least 10 supporting ESTs (Table 4). A family of lipid-transfer protein (represented by 77 ESTs) was most abundant. They are known to be involved in biotic and abiotic stress responses [50]. Additionally, transcripts related to Bet v I allergen family, antimicrobial protein, germin-like protein, and many photosynthetic pathway genes were also highly abundant. The supporting ESTs represent between 1 and 9 unique contigs (Table 4; Additional file 5: Table S5). The supplemental Additional file 5: Table S5 provides details on 149 annotated sequences with supporting ESTs. The examination of the complete set shows that several growth factors, disease responsive genes, transcription factors, and photosynthetic mechanism proteins are represented by multiple ESTs (Table 4; Additional file 5: Table S5). These may be the result of multigene families, in addition to the inherent redundancy of ESTs in nonnormalized cDNA libraries [37].

High abundance of genes involved in photosynthesis, growth and transcription factors is quite expected because the cDNA library was constructed from needles of actively growing black spruce seedlings in the greenhouse conditions. Abundance of stress and disease responsive genes expressed in black spruce seedlings growing under optimal greenhouse conditions suggest

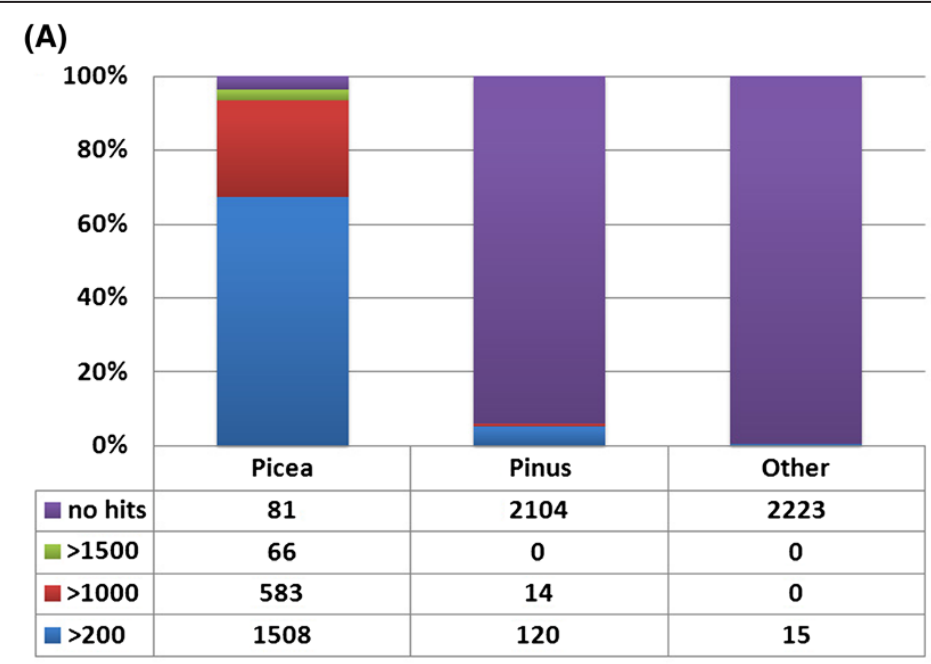

(B)

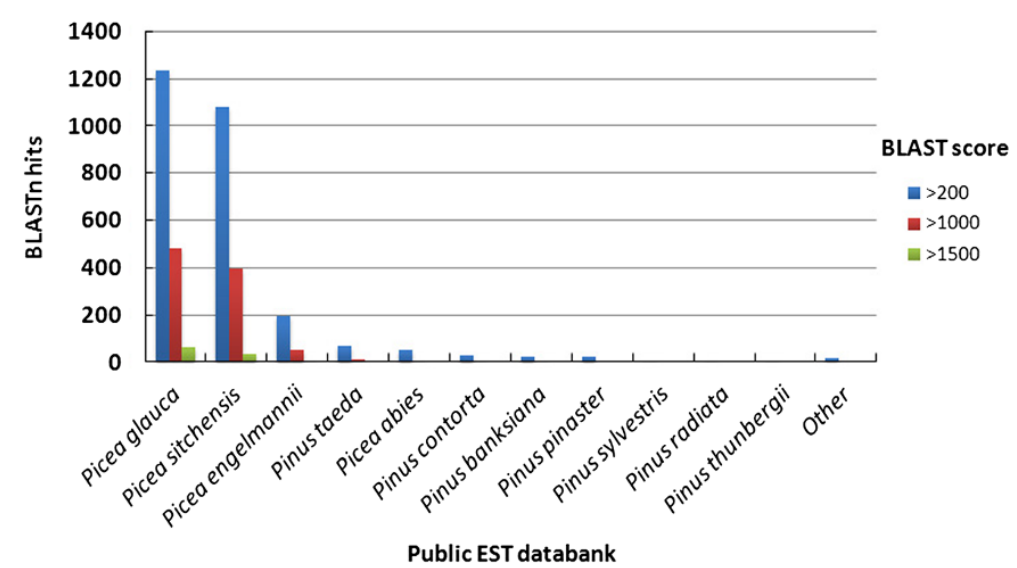

Figure 5 Conservation between Picea mariana unique sequences and CDNA sequences from other conifer species: (A) BLASTN searches were performed against NCBI's est_others repository and those with hits with a minimum e-value of $1 \mathrm{e}-05$ were organized into Picea, Pinus and Other to examine similarity by genus. 18\% of the sequences (493) had no hits within Picea and are therefore likely to be unique to Picea mariana. (B) The same BLASTN searches were divided by species and organized into categories by score: $>200,>1,000$, and > 1,500. The greatest number of hits was observed with Picea glauca and Picea sitchensis. These two species also had the greatest number of nearly identical hits (scores $>1500$ ). 
Table 5 Types and distribution of simple sequence repeats

\begin{tabular}{|c|c|c|}
\hline Type of repeat & Repeat motif & $\begin{array}{c}\% \text { of sequences having repeat } \\
\text { motif }\end{array}$ \\
\hline \multirow{3}{*}{$\begin{array}{l}\text { Pentanucleotide } \\
\text { repeats }\end{array}$} & $(\mathrm{CGCAG}) 4$ & 0.07 \\
\hline & $(T C A G A) 4$ & 0.07 \\
\hline & (TGGTC)4 & 0.07 \\
\hline \multirow{3}{*}{$\begin{array}{l}\text { Tetranucleotide } \\
\text { repeats }\end{array}$} & (ACAT)4 & 0.07 \\
\hline & (CCTG)5 & 0.07 \\
\hline & $($ TAAT)4 & 0.07 \\
\hline \multirow{35}{*}{$\begin{array}{l}\text { Trinucleotide } \\
\text { repeats }\end{array}$} & $(\mathrm{AAC}) 4$ & 0.15 \\
\hline & $(\mathrm{AAG}) 4$ & 0.15 \\
\hline & $(\mathrm{AAT}) 4$ & 0.07 \\
\hline & $(\mathrm{ACG}) 4$ & 0.07 \\
\hline & $(A G A) 4$ & 0.07 \\
\hline & (AGC)4or6 & 0.11 or 0.07 \\
\hline & (AGG)4or5 & 0.22 or 0.07 \\
\hline & $($ ATA $) 5$ & 0.07 \\
\hline & (ATC)4 & 0.11 \\
\hline & (ATG)4 & 0.11 \\
\hline & (CAC)5or6 & 0.07 or 0.07 \\
\hline & (CAG)4or5or6 & 0.15 or 0.11 or 0.07 \\
\hline & (CAT)4 & 0.11 \\
\hline & $(C C A) 5$ & 0.07 \\
\hline & $(\mathrm{CCG}) 4$ & 0.07 \\
\hline & (CGC)5 & 0.07 \\
\hline & $(\mathrm{CGG}) 4$ & 0.07 \\
\hline & (CTC)4or5 & 0.07 or 0.11 \\
\hline & (CTG)4or5 & 0.11 or 0.11 \\
\hline & (CTT)4or6 & 0.11 or 0.07 \\
\hline & $(\mathrm{GAA}) 4$ or5 & 0.22 or 0.07 \\
\hline & $(\mathrm{GAC}) 8$ & 0.07 \\
\hline & (GAG)4or8 & 0.11 or 0.07 \\
\hline & $(G A T) 4$ & 0.07 \\
\hline & $(G C A) 4$ & 0.15 \\
\hline & (GCC)6 & 0.07 \\
\hline & $(\mathrm{GCT}) 4$ & 0.11 \\
\hline & (GGA)4or5 & 0.22 or 0.07 \\
\hline & $(\mathrm{TAA}) 4$ & 0.07 \\
\hline & $(\mathrm{TAG}) 4$ & 0.07 \\
\hline & (TAT)5or6 & 0.07 or 0.07 \\
\hline & (TCA)4 & 0.11 \\
\hline & (TCC)4or5 & 0.15 or 0.07 \\
\hline & (TCT)4or5 & 0.11 or 0.15 \\
\hline & $(T G A) 4$ & 0.07 \\
\hline
\end{tabular}

Table 5 Types and distribution of simple sequence repeats (Continued)

\begin{tabular}{|c|c|c|}
\hline & (TGC)4 & 0.07 \\
\hline & $(\mathrm{TGG}) 6$ & 0.07 \\
\hline & (TTC)4 & 0.26 \\
\hline & (TTG)4 & 0.11 \\
\hline \multirow{12}{*}{$\begin{array}{l}\text { Dinucleotide } \\
\text { repeats }\end{array}$} & (AC)4or5or6 & 0.77 or 0.18 or 0.11 \\
\hline & (AG)4or5 & 1.39 or 0.15 \\
\hline & $\begin{array}{l}\text { (AT) } \\
40 r 5 \text { or6or7or8 }\end{array}$ & $\begin{array}{c}2.27 \text { or } 0.70 \text { or } 0.11 \text { or } 0.15 \text { or } \\
0.15\end{array}$ \\
\hline & (CA)4or5or6 & 0.81 or 0.07 or 0.11 \\
\hline & (CG)4or5or6 & 0.29 or 0.11 or 0.07 \\
\hline & $(\mathrm{CT}) 40 r 5$ & 0.84 or 0.18 \\
\hline & (GA)4or5or6 & 0.99 or 0.07 or 0.18 \\
\hline & (GC)4or5or6 & 0.40 or 0.15 or 0.07 \\
\hline & (GT)4or5or6 & 0.37 or 0.07 or 0.07 \\
\hline & (TA)4or5or6or7 & 2.05 or 0.37 or 0.11 or 0.11 \\
\hline & (TC)4or5or6 & 1.28 or 0.22 or 0.07 \\
\hline & (TG)4or5 & 0.73 or 0.15 \\
\hline
\end{tabular}

that these genes are also involved in plant functions other than their response to abiotic and biotic stress. Nevertheless, the stress and disease responsive genes identified in our study provide very valuable transcriptomic resource for structural and functional genomics studies in black spruce.

Sequence similarities, life history and ecological traits and evolutionary relationships

Unique sequences were also compared with ESTs from major plant species combined (dbEST database of GenBank, excluding ESTs reported in this study) using BLASTN. As expected, sequence similarity between the P. mariana sequences and published gymnosperm ESTs was high (Figure 5; Additional file 6: Table S6). Results were examined first by genus (Figure 5A) and subsequently by specific species within Picea and Pinus (Figure 5B). A total of 493 sequences did not have a significant BLASTN hit and are therefore considered to be novel sequences. These novel sequences may represent transcripts specific to $P$. mariana related to its speciesspecific traits. As noted earlier, $P$. mariana differs from $P$. glauca, $P$. sitchensis and $P$. engelmannii for many life history, growth, morphological, ecophysiological, adaptive and insect resistance traits $[14,19,20]$. Black spruce is an early successional pioneering species, whereas white and Sitka spruces are late-successional and climax species. It is a slower growing species than white and Sitka spruce. Black spruce unlike white and Sitka spruce can grow on poorly drained, wet organic, loamy clay 
nutrient-poor soils, with low soil temperatures and high moisture contents $[14,19,20]$. Black spruce is less susceptible to some insect diseases, such as spruce budworm (Choristoneura fumiferana), than white spruce [14]. White spruce is very closely related to Engelmann spruce and Sitka spruce, and hybridizes naturally with these species in the zone of overlap [19]. Phylogenetically, black spruce is distinct from white, Sitka and Engelmann spruces [21]. Occurrence of some speciesspecific genes in $P$. mariana is therefore expected. It is noteworthy that despite the relatively smaller $P$. mariana EST dataset as compared to P. glauca, and $P$. sitchensis, a significant number of novel transcripts could be detected in our study. This number may be an over-estimate as some of these novel transcripts may be gene segments or regions from $5^{\prime}$ or $3^{\prime}$ ends of genes sufficiently diverged to escape our similarity criteria.

Among the remaining, 2,238 sequences, 96\% had a hit to a member of the Picea genus and $6 \%$ had significant similarities to a member of the Pinus genus (Figure 5A). When viewing the results by species, Picea glauca and Picea sitchensis had the majority of significant matches, with more than $65 \%$ of the sequences generating a BLAST score $>200$ (Figure 5B). These similarity results suggest that the majority of $P$. mariana genes discovered are homologues (orthologs) of other Picea species genes and may have originated from a common ancestor. The significant similarities with $P$. glauca ESTs is not surprising as both species are sympatric transcontinental boreal species which can hybridize naturally, although rarely [51]. Within Pinus, the greatest number of hits was observed with Pinus taeda (68 unique sequences) as expected since the EST resource generated for that species is very large $(328,662)$. Pinus contorta followed with 30 unique sequence similarities with scores $>200$ (Figure 5B). Only 17 (0.6\%) sequences had significant similarity to another plant species outside of the Picea and Pinus families. These $0.6 \%$ BLAST hits to distant species may represent sequences not well characterized in closely related conifer species.

\section{Simple sequence repeats}

A total of 57 different di-, tri-, tetra-, and penta-nucleotide repeats were identified among the $P$. mariana ESTs (Table 5). These were represented by 12 dinucleotide, 39 trinucleotide, three tetranucleotide, and three pentanucleotide repeats. Dinucleotide motifs were the most frequent (72\%), followed by trinucleotide motifs, which constitute $26 \%$ of total number of SSRs. Among the dinucleotide and trinucleotide repeats AT, and CAG motifs, respectively, were the most abundant. SSR markers have been developed from some of these SSR-containing sequences and mapped on a black spruce genetic map [52]. The SSR markers developed and other that can be developed in the future from the black spruce EST sequences reported here provide a highly valuable resource for various population and conservation genetic studies in black spruce and other conifers.

\section{Conclusions}

We report here the first EST resource of high quality for a widely-distributed, ecologically and economically important boreal conifer, black spruce. Despite the relatively small number of EST sequences compared to Picea glauca and P. sitchensis, our study identified 493 novel transcripts with no nucleotide similarity with $\mathrm{dbEST}$, and therefore, represent important addition to dbEST. We have identified genes involved in 36 molecular functions and 90 biological processes. Genes involved in stress response, photosynthetic pathway and growth were most abundant in the ESTs. We have identified 216 full-length genes, ranging from 18 to 265 amino acids in length. The sequences showed the greatest similarities to ESTs from the congeneric and sympatric species, Picea glauca. Black spruce ESTs containing 57 different di-, tri-, tetra-, and penta-nucleotide repeats were identified. These sequences could be used for the development of microsatellite DNA markers.

The ESTs, and their annotations provide a valuable genomics resource to the forest tree genomics community in specific and plant genomics community in general. Markers developed from some of the EST sequences have already been mapped on a black spruce genetic linkage map [52]. The ESTs reported will provide an excellent resource for future assembly and annotation of transcriptome sequences from the NGS platforms, as well as for annotation of the spruce whole genome sequences. A comparison of 454 and Sanger reads showed that Sanger reads can improve the assembly and annotation of the 454 datasets $[13,53]$.

\section{Availability of supporting data}

All of the 4,594 high quality EST sequences have been deposited into GenBank under the accession numbers dbEST JZ079173 - JZ083766. They have also been submitted to the TreeGenes database admits multiple queries on the occurrence of ESTs in the library and their functional annotation.

\section{Additional files}

Additional file 1: Table S1. Detailed annotation of complete set of black spruce singletons and contigs.

Additional file 2: Table S2. BLASTX similarity results against peptides from five model species: Arabidopsis, Populus, Oryza sativa, and Vitis vinifera, and Physcomitrella patens.

Additional file 3: Table S3. EST singletons and contigs annotated as putative photosynthetic pathway genes. 
Additional file 4: Table S4. Predicted annotation, GenBank accession numbers for the black spruce predicted full length genes.

Additional file 5: Table S5. Estimation of gene expression: Unique EST sequences with 1-9 ESTs.

Additional file 6: Table S6. Sequence similarity results for back spruce unique sequences against $\mathrm{dbEST}$.

\section{Abbreviations}

ESTs: Expressed sequence tags; NR: Non-redundant; GO: Gene ontology; dbEST: EST database; SSRs: Simple sequence repeats; NGS: Next-generation sequencing.

\section{Competing interests}

The authors declare that they have no competing interests.

\section{Authors' contributions}

IKM was partly involved in library construction, Sanger sequencing, quality assurance, sequence analysis and processing, and prepared the first draft of the manuscript. JW carried out sequence assembly, annotation, submitted sequences to public databases, and contributed to manuscript preparation; OPR is the Principal Investigator of the Spruce Genomics Project and contributed to the project conception, secured project funding, provided overall project direction and guidance, and contributed to the manuscript preparation and revision. All authors read and approved the final manuscript.

\section{Acknowledgements}

We thank John Major for providing black spruce seedlings, Dr Daoquian Xiang for assistance with CDNA library construction and EST sequencing, Taralynn Cluney, Brent Higgins and Waleed Abousamak for help in running LiCor sequencing gels, and Minyoung Choi and Ben Figueroa for assistance with bioinformatics analysis. The research was funded by a Natural Sciences and Engineering Research Council of Canada (NSERC) Strategic Project grant (STPGP 234783 - 00) to O.P. Rajora. I.K. Mann was financially supported by NSERC Strategic Grants funds (STPGP 234783 - 00) to O.P. Rajora and Dalhousie University Graduate Scholarship. O.P. Rajora held the Stora Enso Senior Chair in Forest Genetics and Biotechnology at Dalhousie University, which was supported by Stora Enso Port Hawkesbury Ltd., and the Senior Canada Research Chair in Forest and Conservation Genomics and Biotechnology at UNB, which was supported by the Canada Research Chair Program (CRC950-201869).

\section{Author details}

${ }^{1}$ Forest Genetics and Biotechnology Group, Department of Biology, Life Sciences Centre, Dalhousie University, 1355 Oxford Street, Halifax, NS B3H 4J1, Canada. ${ }^{2}$ Faculty of Forestry and Environmental Management, University of New Brunswick, P.O. Box 44000, 28 Dineen Drive, Fredericton, NB E3B 5A3, Canada. ${ }^{3}$ Department of Plant Sciences, University of California at Davis, One Shields Avenue MC4, Davis, California 95616, USA.

\section{Received: 1 October 2013 Accepted: 8 October 2013}

Published: 11 October 2013

\section{References}

1. Pavy N, Laroche J, Bousquet J, Mackay J: Large-scale statistical analysis of secondary xylem ESTs in pine. Plant Mol Biol 2005, 57:203-224.

2. Kirst M, Johnson AF, Baucom C, Ulrich E, Hubbard K, Staggs R, Paule C, Retzel E, Whetten R, Sederoff R: Apparent homology of expressed genes from wood-forming tissues of loblolly pine (Pinus taeda L.) with Arabidopsis thaliana. Proc Natl Acad Sci USA 2003, 100:7383-7388.

3. Sterky F, Regan S, Karlsson J, Hertzberg M, Rohde A, Holmberg A, Amini B, Bhalerao R, Larsson M, Villarroel $R$, et al: Gene discovery in the wood-forming tissues of poplar: Analysis of 5,692 expressed sequence tags. Proc Natl Acad Sci USA 1998, 95(22):13330-13335.

4. Ralph S, Chun H, Kolosova N, Cooper D, Oddy C, Ritland C, Kirkpatrick R, Moore R, Barber S, Holt R, et al: A conifer genomics resource of 200,000 spruce (Picea spp.) ESTs and 6,464 high-quality, sequence-finished full-length cDNAs for Sitka spruce (Picea sitchensis). BMC Genomics 2008, 9(1):484.

5. Ewing R, Poirot O, Claverie JM: Comparative analysis of the Arabidopsis and rice expressed sequence tag (EST) sets. In Silico Biol 1999, 1(4):197-213.
6. Parchman T, Geist K, Grahnen J, Benkman C, Buerkle CA: Transcriptome sequencing in an ecologically important tree species: assembly, annotation, and marker discovery. BMC Genomics 2010, 11(1):180.

7. Metzker ML: Sequencing technologies the next generation. Nat Rev Genet 2010, 11(1):31-46.

8. Zhang J, Chiodini R, Badr A, Zhang G: The impact of next-generation sequencing on genomics. J Genet Genom 2011, 38(3):95-109.

9. Birol I, Raymond A, Jackman SD, Pleasance S, Coope R, et al: Assembling the $20 \mathrm{~Gb}$ white spruce (Picea glauca) genome from whole-genome shotgun sequencing data. Bioinformatics 2013. doi:10.1093/bioinformatics/btt1/78.

10. Nystedt B, Street N, Wetterbom A, Zuccolo A, Lin Y-C, et al: The Norway spruce genome sequence and conifer genome evolution. Nature 2013 doi.10.1038/nature12211.

11. Vera JC, Wheat CW, Fescemyer HW, Frilander MJ, Crawford DL, Hanski I, Marden JH: Rapid transcriptome characterization for a nonmodel organism using 454 pyrosequencing. Mol Ecol 2008, 17(7):1636-1647.

12. Hudson ME: Sequencing breakthroughs for genomic ecology and evolutionary biology. Mol Ecol Resour 2008, 8(1):3-17.

13. Ueno S, Le Provost G, Leger V, Klopp C, Noirot C, Frigerio J-M, Salin F, Salse J, Abrouk M, Murat F, et al: Bioinformatic analysis of ESTs collected by Sanger and pyrosequencing methods for a keystone forest tree species: oak. BMC Genomics 2010, 11(1):650.

14. Viereck LA, Johnston WF: Picea mariana (Mill.) B.S.P. - Black spruce. In Silvics of North America vol. 1, Conifers. U.S.D.A. Forest Service Handbook 654. Edited by Burns RM, Honkala BH. Washington, DC, USA: U.S.D.A. Forest Service; 1990.

15. Morgenstern EK, Wang BSP: Trends in forest depletion, seed supply, and reforestation in Canada during the past four decades. Forest Chron 2001, 6:1014-1021.

16. Bai C, Alverson WS, Follansbee A, Waller DM: New reports of nuclear DNA content for 407 vascular plant taxa from the United States. Ann Botany 2012, 110:1623-1629.

17. National Center for Biotechnology Information. http://www.ncbi.nlm.nih.gov/.

18. Rigault P, Boyle B, Lepage P, Cooke JEK, Bousquet J, Mackay JJ: A white spruce gene catalog for conifer genome analyses. Plant Physiol 2011, 157:14-28.

19. Ninestaedt H, Zasada JC: Picea glauca (Moench) Voss White spruce. In Silvics of North America vol. 1, Conifers. U.S.D.A. Forest Service Handbook 654. Edited by Burns RM, Honkala BH. Washington, DC, USA: U.S.D.A. Forest Service; 1990.

20. Harris AS: Picea sitchensis (Bong.) Carr. White spruce. In Silvics of North America vol. 1, Conifers. U.S.D.A. Forest Service Handbook 654. Edited by Burns RM, Honkala BH. Washington, DC, USA: U.S.D.A. Forest Service; 1990.

21. Ran J-H, Wei X-X, Wang X-Q: Molecular phylogeny and biogeography of Picea (Pinaceae): Implications for phylogeographcal studies using cytoplasmic haplotypes. Mol Phylogenet Evol 2006, 41:405-419.

22. Allona I, Quinn M, Shoop E, Swope K, St Cyr S, Carlis J, Riedl J, Retzel E, Campbell $M$, Sederoff $R$, et al: Analysis of xylem formation in pine by cDNA sequencing. Proc Natl Acad Sci USA 1998, 95:9693-9698.

23. Fernandez-Pozo N, Canales J, Guerrero-Fernandez D, Villalobos D, Diaz-Moreno S, Bautista R, Flores-Monterroso A, Guevara MA, Perdiguero P, Collada C, et al: EuroPineDB: a high-coverage web database for maritime pine transcriptome. BMC Genomics 2011, 12(1):366.

24. Lorenz WW, Ayyampalayam S, Bordeaux J, Howe G, Jermstad K, Neale D, Rogers D, Dean JD: Conifer DBMagic: a database housing multiple de novo transcriptome assemblies for 12 diverse conifer species. Tree Genet Genom 2012, 8(6):1477-1485.

25. Pavy N, Paule C, Parsons L, Crow J, Morency M-J, Cooke J, Johnson J, Noumen E, Guillet-Claude C, Butterfield Y, et al: Generation, annotation, analysis and database integration of 16,500 white spruce EST clusters. BMC Genomics 2005, 6(1):144

26. Chen J, Uebbing S, Gyllenstrand N, Lagercrantz U, Lascoux M, Kallman T: Sequencing of the needle transcriptome from Norway spruce (Picea abies Karst L.) reveals lower substitution rates, but similar selective constraints in gymnosperms and angiosperms. BMC Genomics 2012, 13(1):589.

27. Chang S, Puryear J, Cairney J: A simple and efficient method for isolating RNA from pine trees. Plant Mol Biol Report 1993, 11(2):113-116.

28. Wegrzyn JL, Lee JM, Tearse BR, Neale DB: TreeGenes: a forest tree genome database. Int J Plant Genom 2008, 2008. Article ID 412875, 7 pages, doi: 10.1155/2008/412875.

29. Ewing B, Hillier L, Wendl MC, Green P: Base-calling of automated sequencer traces using phred. I. Accuracy assessment. Genome Res 1998, 8:175-185. 
30. Ewing B, Green P: Base-calling of automated sequencer traces using phred. II. Error probabilities. Genome Res 1998, 8:186-194.

31. Valledor L, Jorrín JV, Rodríguez JL, Lenz C, Meijón M, Rodríguez R, Cañal MJ: Combined proteomic and transcriptomic analysis identifies differentially expressed pathways associated to Pinus radiata needle maturation. J Proteome Res 2010, 9(8):3954-3979.

32. Altschul SF, Gish W, Miller W, Myers EW, Lipman DJ: Basic local alignment search tool. J Mol Biol 1990, 215(3):403-410.

33. Edgar RC: Search and clustering orders of magnitude faster than BLAST. Bioinformatics 2010, 26(19):2460-2461.

34. Temnykh S, DeClerck G, Lukashova A, Lipovich L, Cartinhour S, McCouch S: Computational and experimental analysis of microsatellites in rice (Oryza sativa L.): frequency, length variation, transposon associations, and genetic marker potential. Genome Res 2001, 11(8):1441-1452.

35. Dendrome project. http://dendrome.ucdavis.edu/dfgp/about.html.

36. Rounsley SD, Glodek A, Sutton G, Adams MD, Somerville CR, Venter JC, Kerlavage AR: The construction of Arabidopsis expressed sequence tag assemblies (a new resource to facilitate gene identification). Plant Physiol 1996, 112(3):1177-1183.

37. Kinlaw CS, Neale DB: Complex gene families in pine genomes. Trends Plant Sci 1997, 2:356-359.

38. Nagaraj SH, Gasser RB, Ranganathan S: A hitchhiker's guide to expressed sequence tag (EST) analysis. Brief Bioinform 2007, 8(1):6-21.

39. Adams MD, Kelley JM, Gocayne JD, Dubnick M, Polymeropoulos MH, Xiao H, Merril CR, Wu A, Olde B, Moreno RF, et al: Complementary DNA sequencing: expressed sequence tags and human genome project. Science 1991, 252(5013):1651-1656.

40. Rai HS, Reeves PA, Peakall R, Olmstead RG, Graham SW: Inference of higher-order conifer relationships from a multi-locus plastid data set. Botany 2008, 86:658-669.

41. Etscheid M, Klümper S, Riesner D: Accumulation of a metallothionein-like mRNA in norway spruce under environmental stress. J Phytopathol 1999, 147(4):207-213.

42. Maret W: The Function of Zinc Metallothionein: A link between cellular zinc and redox state. J Nutrit 2000, 130:1455S-1458S.

43. Zhou G-K, Xu Y-F, Liu J-Y: Characterization of a rice class II metallothionein gene: Tissue expression patterns and induction in response to abiotic factors. J Plant Physiol 2005, 162(6):686-696.

44. Liu P, Goh C-J, Loh C-S, Pua E-C: Differential expression and characterization of three metallothionein-like genes in Cavendish banana (Musa acuminata). Physiologia Plantarum 2002, 114(2):241-250.

45. Dynan WS, Tjian R: Control of eukaryotic messenger RNA synthesis by sequence-specific DNA-binding proteins. Nature 1985, 316(6031):774-778

46. Tandre $K$, Albert VA, Sundås $A$, Engström P: Conifer homologues to genes that control floral development in angiosperms. Plant Mol Biol 1995, 27(1):69-78.

47. Sundström J, Engström P: Conifer reproductive development involves B-type MADS-box genes with distinct and different activities in male organ primordia. Plant J 2002, 31(2):161-169.

48. Eulgem T, Rushton PJ, Robatzek S, Somssich IE: The WRKY superfamily of plant transcription factors. Trends Plant Sci 2000, 5(5):199-206.

49. Rushton PJ, Somssich IE, Ringler P, Shen QJ: WRKY transcription factors. Trends Plant Sci 2010, 15(5):247-258.

50. Sabala I, Elfstrand M, Farbos I, Clapham D, von Arnold S: Tissue-specific expression of $\mathrm{Pa} 18$, a putative lipid transfer protein gene, during embryo development in Norway spruce (Picea abies). Plant Mol Biol 2000, 42(3):461-478

51. Little EL Jr, Pauley SS: A natural hybrid between black and white spruce in Minnesota. Am Midland Natur 1958, 60:202-211.

52. Kang B-Y, Mann IK, Major JE, Rajora OP: Near-saturated and complete genetic linkage map of black spruce (Picea mariana). BMC Genom 2010, 11(1):515.

53. Tedersoo L, Nilsson RH, Abarenkov K, Jairus T, Sadam A, Saar I, Bahram M, Bechem E, Chuyong G, Köljalg U: 454 Pyrosequencing and Sanger sequencing of tropical mycorrhizal fungi provide similar results but reveal substantial methodological biases. New Phytolog 2010, 188(1):291-301.

doi:10.1186/1471-2164-14-702

Cite this article as: Mann et al:: Generation, functional annotation and comparative analysis of black spruce (Picea mariana) ESTs: an important conifer genomic resource. BMC Genomics 2013 14:702.

\section{Submit your next manuscript to BioMed Central and take full advantage of:}

- Convenient online submission

- Thorough peer review

- No space constraints or color figure charges

- Immediate publication on acceptance

- Inclusion in PubMed, CAS, Scopus and Google Scholar

- Research which is freely available for redistribution 